\title{
NueVos Riesgos laborales. La tutela de loS TRABAJADORES AGRARIOS ANTE ENFERMEDADES PROFESIONALES PRODUCIDAS POR AGROTÓXICOS EN Argentina y CHILE
}

[New workplace risks. Protection of agricultural workers facing professional diseases caused by pesticides in Argentina and Chile]

\section{Norma Elizabeth LeVRAND*}

\begin{abstract}
RESUMEN
La tutela jurídica de los trabajadores frente a enfermedades profesionales mediante técnicas actuariales se ve conmovida ante la aparición de riesgos que son efectos secundarios del desarrollo científico-tecnológico. Se intenta describir las inconsistencias de la regulación jurídica laboral a partir del análisis comparativo de legislación, en Argentina y Chile, sobre un caso testigo: los riesgos sufridos por trabajadores agropecuarios debido a la utilización de productos agrotóxicos.

\section{Palabras clave}

Enfermedades profesionales sociedad del riesgo - agrotóxicos.
\end{abstract}

\begin{abstract}
The legal protection of workers facing professional diseases through actuarial techniques is affected by the appearance of risks that are secondary effects of scientific and technological development. We attempt to describe the inconsistencies of labor law based on the comparative analysis of legislation in Argentina and Chile on a case study: the risks suffered by agricultural workers due to the use of pesticidas.
\end{abstract}

\section{KeYWORDS}

Professional diseases - risk society - pesticides.

ReCibido el 4 de marzo y APROBADO el 1 de diciembre de 2016

* Becaria Doctoral del Consejo Nacional de Investigaciones Científicas y Técnicas, Docente Adjunta del Seminario de Relaciones Laborales de la Universidad Autónoma de Entre Ríos, Jefa de Trabajos Prácticos de Ciencia, Tecnología y Sociedad en la Universidad Nacional del Litoral. Dirección Postal: Cándido Pujato 2751, 1er. Piso, Ala Oeste, Santa Fe, C.P. 3000, Provincia de Santa Fe, Argentina. E-Dirección: nlevrand@fcjs.unl.edu.ar 


\section{INTRODUCCIÓN}

Es un lugar común afirmar que los riesgos laborales se intensificaron con el advenimiento de la sociedad industrial moderna. En este contexto, el Derecho del Trabajo acuñó la idea de seguridad física de los trabajadores. Mientras los riesgos laborales fueron mensurados por los daños que causaban (mayormente) las maquinarias provenientes de la Revolución Industrial, la legislación se sirvió de técnicas actuariales de cálculo de los factores de exposición como así también de las indemnizaciones correspondientes. En este sentido, los riesgos asegurables presuponían una racionalidad de cálculo basada en efectos definidos, regulares, mensurables aunque relativamente impredecibles. Estas características permitían regularlos y gobernarlos ${ }^{1}$. Este gobierno se institucionaliza a partir de la "mutualización" de los riesgos a través de la técnica del seguro obligatorio, en un proceso de construcción de una 'sociedad de la seguridad'2.

En las últimas décadas del siglo XX, el afianzamiento de las técnicas de cálculo actuarial, sumado al surgimiento de nuevas tecnologías y nuevas formas de producción generaron procesos y dispositivos que buscaron implementar mayor seguridad, al tiempo que también se generaban riesgos desconocidos. Si bien se mejoraron enormemente las técnicas para evitar los daños físicos provenientes de aquellas herramientas mecánicas que a principios del siglo XX aún exponían a los trabajadores a riesgos altísimos; como fruto de las nuevas tecnologías, aparecieron nuevos riesgos, desconocidos tanto en sus causas como en sus consecuencias. Ello da cuenta de la paradoja de que la producción científica y tecnológica desata una serie de riesgos que son efectos secundarios, latentes o colaterales del desarrollo ${ }^{3}$. La característica principal de estos riesgos es que los científicos no pueden desentrañar el alcance que tendrán en el futuro, ni la posibilidad de que se concreticen en daños efectivos.

En la sociedad industrial, los riesgos del desempleo y la pobreza estaban circunscritos a ciertas clases sociales, en cambio esta nueva configuración de los riesgos (que incluye desde ataques terroristas hasta desastres y contaminación ambientales) no distinguen entre ricos y pobres, empre-

${ }^{1}$ HaIDAR, Victoria, Trabajadores en riesgo. Una sociología histórica de la biopolitica de la población asalariada en Argentina (1890-1915) (Buenos Aires, Prometeo, 2008), p 24.

2 CASTEl, Robert, El ascenso de las incertidumbres. Trabajo, protecciones, estatuto del individuo ( $2^{\mathrm{a}}$ ed., traducción de Víctor Goldstein, Buenos Aires, Fondo de Cultura Económica, 2012), p. 30.

3 BeCK, Ulrich, La sociedad del riesgo global (trad. Jesús Alborés Rey, Madrid, Siglo Veintiuno, 2002). 
sarios, comerciantes o asalariados. Ello no significa que el paradigma de la desigualdad social haya desaparecido, simplemente ha mutado de una sociedad de reparto de riqueza a una sociedad de reparto de riesgos. Esta nueva condición es denominada sociedad del riesgo ${ }^{4}$.

En este contexto, el discurso de distintos organismos ha advertido sobre la creciente necesidad de alimentos ${ }^{5}$ desde la finalización de la segunda Guerra Mundial. Ello justificó el inicio de la era química en la agricultura, que resultó en el diseño de una serie de técnicas de cultivo y nuevas formas de lucha contra las plagas a nivel mundial.

Entre estas nuevas tecnologías se encuentra la utilización de componentes químicos para el control de plagas de origen animal y vegetal en los cultivos. Estos componentes químicos, comúnmente denominados agroquímicos, o plaguicidas, instauraron una verdadera revolución en la agricultura durante los años 60 y 70 . En ese momento la relación costoefectividad los tornó altamente aplicables, incluso preventivamente.

No obstante, al poco tiempo se demostró que su uso no era inocuo, sino que generaba efectos colaterales tanto en el medio ambiente como en la salud de las personas. Entre estas últimas, resultaban particularmente afectados aquellos trabajadores cuya labor implicaba la manipulación de productos agrotóxicos ${ }^{6}$.

El objetivo del trabajo es describir las inconsistencias del sistema tutelar del trabajador para brindarle protección frente a los nuevos riesgos socialmente producidos, que poseen las características antes mencionadas y que reconfiguran los riesgos laborales de la modernidad. Para lograr el mismo, el estudio de un caso testigo funcionará como núcleo que, a partir de un

${ }^{4}$ BECK, Ulrich, La sociedad del riesgo. Hacia una nueva modernidad (trad. Jorge Navarro, Daniel Jiménez y Ma Rosa Borrás, Buenos Aires, Paidós, 1998).

5 Por ejemplo, el informe 'Perspectivas Alimentarias' elaborado por la Food and Agriculture Organisation of the United Nations, de junio de 2008 destaca que "el costo de los alimentos continúa aumentando en todo el mundo. La intensa competencia por los suministros internacionales reducidos de trigo, maíz, arroz, y muchos otros productos agrícolas, no da señales de ceder y trae aparejados riesgos de carestía de alimentos y de disturbios civiles en los países de bajos ingresos. Urge, por lo tanto, la necesidad de adoptar estrategias a corto y largo plazo para prevenir tales riesgos".

${ }^{6}$ La palabra 'agrotóxico' alude al conjunto de productos químicos, fitofarmacéuticos o fitosanitarios que son utilizados en agricultura para combatir diversas plagas. En este sentido, pueden ser incluidos dentro de la definición los plaguicidas, pesticidas, defoliantes y fitorreguladores. La disputa científica existente en cuanto a los riesgos de su utilización para la vida humana y el ambiente (y que será presentada más adelante) presenta como alternativas supuestamente neutrales las palabras 'plaguicidas' o 'agroquímicos'. Reconociendo que el lenguaje no es neutral, optamos por la primera expresión a fin de poner de manifiesto la posibilidad de toxicidad para seres humanos de estos productos. 
estudio de legislación comparativa, permitirá elaborar elementos teóricos que puedan ser extrapolados a otras situaciones producidas por la sociedad del riesgo en el ámbito laboral.

El caso seleccionado es la exposición de los trabajadores a factores de riesgo por la ejecución de sus tareas en relación de dependencia en el ámbito rural, debido a la utilización de productos agrotóxicos en Argentina y Chile. La fundamentación de elección de este caso se realiza a partir de constatar que "a nivel mundial el tres por ciento de los trabajadores en la agricultura que están expuestos al contacto con plaguicidas sufre de un episodio de intoxicación aguda por año" ". Este caso será estudiado comparativamente en dos legislaciones, la argentina y la chilena. En Argentina, el índice de accidentes y enfermedades profesionales del sector agropecuario es mayor a la media del sistema y sólo menor al sector de construcción ${ }^{8}$. Por su parte, en Chile, el índice de enfermedades profesionales en agricultura se encuentra entre las más altas, encontrándose entre las tres actividades más riesgosas, apenas superado por las industrias manufactureras y el transporte?

El sistema de tutela laboral vigente en Argentina prevé la protección del trabajador ante las contingencias de accidentes de trabajo y enfermedades profesionales. La ley No 24.557 denominada Ley de Riesgos del Trabajo (en adelante, LRT) fue aprobada en 1995 y basa el sistema de protección ante enfermedades laborales en la inclusión de las mismas en un listado que identifica los agentes de riesgo, cuadros clínicos, exposición y actividades en capacidad de determinar la enfermedad (art. 6 inc. 1). Las enfermedades no incluidas en el listado no son resarcibles, existiendo como excepción un procedimiento ante un órgano administrativo creado por la misma ley, para determinar que, en el caso concreto, la enfermedad ha sido "provocada por causa directa e inmediata de la ejecución del trabajo, excluyendo la influencia de los factores atribuibles al trabajador o ajenos al trabajo" ${ }^{10}$.

7 Chelala, César, Un reto constante: los plaguicidas y su efecto sobre la salud y el medio ambiente (Washington, Organización Panamericana de la Salud, 2004) p. 8. El autor destaca asimismo que "además de intoxicaciones agudas, la exposición a plaguicidas durante largos períodos a bajo nivel de exposición pueden producir efectos crónicos severos tales como malformaciones congénitas, daños al sistema nervioso central, efectos mutagénicos, distintos tipos de cáncer, daños al sistema inmunitario y lesiones a la piel, los ojos y los pulmones, entre otros".

8 Superintendencia de Riesgos de Trabajo, Índice Anual de Accidentabilidad Laboral según sector económico (1 dígito del CIIU), Año 2014.

9 Superintendencia de Seguridad Social, Estadísticas mensuales años 2015 y 2016, disponible en http://www.suseso.cl/estadisticas-mensuales [consultado el 6/01/2017] y Memoria Anual Sistema Nacional de Seguridad y Salud Laboral, año 2013, p. 50.

${ }^{10}$ Ley No 24.557, art. 6, inc. 2. 
Por su parte, en Chile, la regulación laboral establecida por la ley No 16.744 de 1968 sobre accidentes del trabajo y enfermedades profesionales (en adelante, LATEP) prevé la contratación de un seguro social contra riesgos de accidentes del trabajo y enfermedades profesionales. Esta norma define a la enfermedad profesional como aquella "causada de una manera directa por el ejercicio de la profesión o el trabajo que realice una persona y que le produzca incapacidad o muerte" ${ }^{11}$. Asimismo, se reglamenta la calificación y evaluación de las enfermedades profesionales estableciendo un listado que debe ser revisado, al menos, cada tres años ${ }^{12}$. Este listado relaciona la enfermedad con la exposición a diversos agentes que resulten de la actividad laboral, indicando que la utilización del listado debe realizarse teniendo en cuenta, según proceda, el grado y tipo de exposición y la ocupación que implique un riesgo de exposición específico ${ }^{13}$.

Nuestra hipótesis es que la regulación laboral de Argentina y Chile no cubre estas contingencias. Ello en virtud de que la recepción de una relación de causalidad eficiente entre las patologías derivadas del uso de productos agrotóxicos y el trabajo, sumada a la ausencia de herramientas de gobierno complementarias, impide la protección de los trabajadores frente a un riesgo potencial y novedoso. Potencial por cuanto las evidencias científicas producidas en relación a su existencia son cuestionadas, y novedoso en su forma de producción y efectos (éstos solo se manifiestan a largo plazo).

Para desarrollar esta hipótesis, en el segundo apartado se analizará el sistema de protección de los trabajadores agrarios en Argentina y Chile, haciendo hincapié en la tutela por enfermedades profesionales y en la percepción que los diversos actores sociales realizan de la situación. Esta introducción servirá de base para focalizar el tercer apartado en las inconsistencias que produce este sistema de protección ante los nuevos riesgos generados por la utilización de agrotóxicos. Para ello se abordará relación entre la ciencia y el derecho en la regulación de este riesgo. Esto permitirá considerar el núcleo de la problemática jurídica, esto es, la relación causal en la tutela por enfermedades profesionales, y las posibilidades que ofrecen nuevas teorizaciones jurídicas realizadas para tratar temáticas afines. Finalmente, en la conclusión se dará cuenta de las posibilidades que se ofrecen para lograr una coherencia jurídica del sistema.

${ }^{11}$ Ley No 16.744 , art. 7.

12 Ley No 16.744, art. 7, Decreto No 109, 07/06/1968 y Decreto No 73, 0703/2006.

${ }^{13}$ Lista de Enfermedades Profesionales aprobada el 12/04/2010. 


\section{EL FUNCIONAMIENTO DEL SISTEMA DE PROTECCIÓN DE LOS} TRABAJADORES CONTRA RIESGOS LABORALES

\section{El deber de seguridad y el contrato de trabajo}

El deber de seguridad ínsito en el contrato de trabajo ${ }^{14}$ "evoca el cúmulo de acciones exigibles al empleador para tutelar la integridad psicofísica de cada uno de los trabajadores que dependen de él"15 y genera la responsabilidad de los empleadores por la integridad física y psíquica de los trabajadores ${ }^{16}$. En el derecho común, Lorenzetti los caracteriza como deberes secundarios de conducta, que "nacen con la idea de ensanchar el plexo obligacional" ${ }^{17}$. Ellos se derivan del principio de buena fe y de ellos deriva la responsabilidad contractual del empleador ante su incumplimiento. Si bien coincidimos con la doctrina especializada en calificar dicho deber entre aquellos incluidos en el contrato de trabajo, entendemos que los daños causados con ocasión del trabajo pueden calificarse como manifiestamente aquilianos, puesto que "se trata de situaciones en las que hay un daño a la persona o al patrimonio, distintos de la prestación principal comprometida" ${ }^{18}$.

En esta tesitura, los daños sufridos por el trabajador con motivo de la exposición a agrotóxicos, deben ser diferenciados en dos grupos: por un lado aquellos daños ocasionados por omisión del empleador de proveer los elementos de seguridad necesarios, en cuyo caso, nos encontraremos con un incumplimiento de la prestación accesoria comprometida al contratar, y por ende, en la responsabilidad contractual, causada inmediata y necesariamente por su incumplimiento. Por otra parte, aquellos daños a los trabajadores agrarios ocurridos a pesar de contar con los elementos de seguridad indicados, en virtud del manejo o exposición a productos agrotóxicos. Éstos aún no están certeramente comprobados por la ciencia, como veremos en el apartado siguiente, y son lejanamente perceptibles por los propios actores. Asimismo, no pueden ser incluidos dentro del riesgo profesional al que accedió al momento de contratar, puesto que si bien se

${ }^{14}$ Supiot, Alain, Derecho del Trabajo (trad. Patricia Rubini-Blanco, Buenos Aires, Heliasta, 2008) p. 113.

${ }^{15}$ Ackerman Mario E. (Dir.) - Tosca, Diego (Coord.), Tratado de Derecho del Trabajo (Tomo VI, Santa Fe, Rubinzal Culzoni, 2007), p. 48.

${ }^{16}$ El autor, luego de un análisis de la doctrina, entiende que es una obligación de medios, siendo su objeto no la integridad psicofísica del trabajador, sino la adopción de las medidas necesarias para que éste no sufra un daño personal.

17 Lorenzetti, Ricardo, Tratado de los contratos. Parte general (Santa Fe, Rubinzal Culzoni, 2004) p. 393.

${ }^{18}$ LorenzetTi, cit. (n. 13), p. 594. 
discute el alcance y la posibilidad cierta de que exista tal riesgo, el empleador cubrió el mismo con la provisión de los elementos de seguridad que, a priori, llevarían al resguardo de la salud del trabajador. En este caso, nos encontramos ante una responsabilidad aquiliana, en la cual, el fundamento de la responsabilidad del empleador estará en el deber general del alterum non laedere, y en la que, subsidiariamente, podría ser responsabilizada la empresa creadora del riesgo.

En el modelo jurídico tradicional, de responsabilidad objetiva, guardaba importancia fundamental la prevención de los daños. De hecho, la LRT argentina es simbólica al respecto, al declarar, en su art. $1^{\circ}$, inc. 2 como un objetivo de la ley "reducir la siniestralidad laboral a través de la prevención de los riesgos derivados del trabajo". Esta función exige tanto una acción de los empleadores, que deben cumplir con el deber de seguridad, como de las aseguradoras de riesgos del trabajo, que deben establecer planes de acción para el mejoramiento de las condiciones de higiene y seguridad en las empresas, estando a su cargo, además el control de los mismos ${ }^{19}$.

Pero la aparición de enfermedades relacionadas con el ámbito del trabajo, cuya vinculación en el ámbito científico es controvertida, hace oscilar esta función preventiva. Evidentemente la insuficiente comprobación de la existencia de daños a aquellos trabajadores que utilicen productos agrotóxicos con todos los elementos de seguridad, limita las medidas preventivas que puedan implementarse.

Con lo expuesto queremos esbozar la idea de que los dispositivos de que dispone el derecho ya no son suficientes para garantizar seguridad a los trabajadores. Y ello conmueve los fundamentos mismos del Derecho Laboral, nacido para proteger la indemnidad de los trabajadores.

\section{La protección de los trabajadores agrarios en Argentina}

Los trabajadores agrarios fueron sujetos diferenciados de tutela en Argentina desde la aparición, en 1944 del Estatuto del Peón Rural. En 2011 se sancionó la ley No 26.727 estableciendo el Régimen Nacional del Trabajo Agrario, que instituye condiciones mínimas de seguridad en el trabajo y dispone el deber del empleador de mantener estas condiciones a favor del trabajador ${ }^{20}$. Para el caso de accidentes y enfermedades profesionales, es

${ }^{19}$ Ley No 24.557, art. 4 inc. 2 y 4.

${ }^{20}$ Ley No 26.727, Art. 45: "Higiene y seguridad. El trabajo agrario deberá realizarse en adecuadas condiciones de higiene y seguridad a fin de evitar enfermedades profesionales o accidentes de trabajo.

El empleador deberá hacer observar las pausas y limitaciones a la duración del trabajo establecidas en esta ley y demás normas reglamentarias o complementarias, y adoptar las medidas que según el tipo de trabajo, la experiencia y la técnica sean necesarias para 
aplicable la LRT, la cual originalmente estableció un listado cerrado y de triple columna para identificar las enfermedades profesionales reconocidas (listado aprobado por el Decreto No 658/96). Esta hermeticidad intentó ser atenuada por el Decreto No 1278/2000 que facultó a declarar profesionales ciertas enfermedades no listadas, y por lo cual ha sido calificada como mixta, ya que combina definición con listado ${ }^{21}$.

Dentro del mismo, podemos encontrar el agente plaguicidas órgano-fosforados y carbamatos asociado a intoxicaciones ocurridas en ocasión del trabajo, las cuales se clasifican en asintomáticas, agudas y agudas severas, lo que excluye otras enfermedades a las que se exponen los trabajadores agrarios.

En primer lugar, puede criticarse que sólo se mencionen los plaguicidas organo-fosforados y carbamatos que son un tipo especial de insecticida, dejando de lado los herbicidas, los fungicidas, rodenticidas y nematocidas, compuestos que pueden ser incluidos en el grupo de los agrotóxicos. Por otra parte, sólo se hace referencia a enfermedades cuyos síntomas son de aparición temprana (especialmente intoxicaciones), excluyendo aquellas que pueden manifestarse incluso una vez extinguida la relación laboral (como el cáncer) y cuyo riesgo es científicamente incierto aún ${ }^{22}$.

tutelar la integridad psicofisica y la dignidad de los trabajadores, debiendo evitar los efectos perniciosos de las tareas penosas, riesgosas o determinantes de vejez o agotamiento prematuro, asi como también, los derivados de ambientes insalubres o ruidosos.

Asimismo, estará obligado a observar las disposiciones legales y reglamentarias pertinentes sobre higiene y seguridad en el trabajo.

El trabajador podrá rehusarse a la prestación de trabajo, sin que ello le ocasione pérdida o disminución de la remuneración, si el mismo le fuera exigido en transgresión a tales condiciones, siempre que exista peligro inminente de daño o se hubiera configurado el incumplimiento de la obligación mediante constitución en mora o si, habiendo el organismo competente declarado la insalubridad del lugar, el empleador no realizara los trabajos o no proporcionara los elementos que dich a autoridad establezca."

Artículo 46: "Elementos de seguridad. Suministro por el empleador. Será obligación del empleador la provisión de elementos de seguridad y protectores personales cuando por razones derivadas de las formas operativas propias del trabajo, fuere necesario su uso.

Igual obligación le corresponde respecto de los elementos de protección individual cuando, el trabajador realizare tareas a la intemperie, en caso de lluvia, terrenos anegados u otras situaciones similares, de acuerdo a lo que dispusiere la Comisión Nacional de Trabajo Agrario (CNTA).

Cuando el trabajador debiere realizar tareas peligrosas para su salud, el empleador deberá instruirlo sobre las adecuadas formas de trabajo y suministrar los elementos de protección personal que fueren necesarios."

${ }^{21}$ ACKerman, cit. (n. 15), p. 50.

${ }^{22}$ Esto repercute en los índices de siniestralidad del sector, dado que estas enfermedades no son denunciables $y$, por ende, no forman parte de las estadísticas 
Ahora bien, el trabajador víctima de una enfermedad causada por un agrotóxico que no figura en el listado del Decreto No 658/96, en principio tendría la posibilidad de concurrir a la Comisión Médica a fin de que ésta declarase, para el caso concreto, el carácter laboral de la enfermedad, de acuerdo a lo dispuesto por el art. 6 ap. 2 b) de la LRT. Ello, siempre y cuando pudiese probar la relación causal entre la enfermedad y el trabajo, lo cual justifica la profundización de este elemento jurídico que realizaremos en el apartado III.2.

Finalmente, los trabajadores agrarios cuentan, como organismo paritario, con la Comisión Nacional de Trabajo Agrario, que actúa en el ámbito del Ministerio de Trabajo, Empleo y Seguridad Social y que tiene entre sus funciones promover el cumplimiento de las normas de higiene y seguridad en el trabajo en el ámbito rural (cfr. Ley No 26.727, art. 89, inc. h). Por aplicación de la misma este organismo ha dictado numerosas resoluciones reglamentando el régimen del trabajador agrario.

Entre ellas, merecen destacarse aquellas que establecen la obligatoriedad de la provisión de equipos de trabajo, de acuerdo a la actividad del trabajador, pero en las cuales no se hace referencia a la obligatoriedad de entregar un equipo suficiente para el fumigado con agrotóxicos ${ }^{23}$. No obstante, por aplicación de lo dispuesto en los artículos 47 y 48 de la ley No 26.727 referente a la limpieza de la ropa de trabajo y el almacenamiento de envases que contienen/contuvieron sustancias tóxicas, la Comisión Nacional de Trabajo Agrario ha reglamentado los deberes del empleador tocantes a estos aspectos ${ }^{24}$.

\section{La protección de los trabajadores agrarios en Chile}

El Código del Trabajo sancionado en 1931 incorporó, como una novedad, la regulación del trabajo agrícola de modo particular. Establecía diversas modalidades para la contratación de estos trabajadores, aunque

estatales repercutiendo particularmente en el índice de letalidad de las enfermedades notificadas.

${ }^{23}$ En este sentido, las recomendaciones internacionales han subrayado la relevancia de contar con equipo de trabajo pertinente desde hace más de dos décadas: "Las prendas necesarias dependerán de los efectos nocivos del producto agroquímico y de la forma en que se utiliza. En la práctica, la información que figura en la etiqueta suministrada con el producto agroquímico suele especificar el nivel de protección requerido. También se pueden facilitar datos detallados sobre la calidad de los diversos artículos, como el espesor mínimo de los guantes o el material con el que deben estar fabricados, por ejemplo neopreno, nitrilo o butilo". FAO Guía sobre seguridad y salud en el uso de productos agroquímicos (Ginebra, Organización de las Naciones Unidas para la Agricultura y la Alimentación, 1993).

${ }^{24} \mathrm{Al}$ respecto, consultar las resoluciones 106 de 2010 y 11 de 2011. 
se le inculpaba la ausencia de normas referentes a la sindicalización de los trabajadores agrícolas, situación que recién fue solucionada, parcialmente, en $1947^{25}$. Luego de diversas reformas, el Código del Trabajo de 1994 regula el trabajo agrícola en los artículos 87 y siguientes y establece normas generales de protección de los trabajadores a partir del artículo 184.

Conforme este último, el empleador tiene la obligación de "proteger eficazmente la vida y salud de los trabajadores, informando de los posibles riesgos y manteniendo las condiciones adecuadas de higiene y seguridad en las faenas, como también los implementos necesarios para prevenir accidentes y enfermedades profesionales". La doctrina ha debatido acerca del alcance de esta obligación patronal, discutiendo acerca del tipo de obligación que genera esta norma para los empleadores. Así, algunos autores indican que es una obligación de seguridad, es decir, una obligación de medios; en tanto otros se inclinan a considerarla una obligación de garantía, por tanto una obligación de resultado. La jurisprudencia, por su parte, ha sancionado la responsabilidad legal por incumplimiento del empleador, adoptando, de este modo, la doctrina que identifica las obligaciones del artículo 184 como obligaciones de resultado ${ }^{26}$.

En 2008 se sanciona la ley No 20.308 que introduce un párrafo en el artículo 92 del Código del Trabajo, relativo a las obligaciones del empleador agrícola. Conforme al mismo, en aquellos casos que el trabajador agrícola tenga contacto con "pesticidas, plaguicidas o productos fitosanitarios tóxicos, según clasificación de la Organización Mundial de la Salud contenida en resolución del Ministerio de Salud", el empleador deberá otorgarle información suficiente sobre su correcta utilización, manipulación, eliminación de residuos y acerca de los riesgos derivados de la exposición. Asimismo, el empleador debe garantizar al trabajador las medidas de seguridad para protegerse de estos productos, tales como implementos, productos de aseo, etc.

Esta norma es complementada con el Decreto No 158 que aprueba el Reglamento sobre Condiciones para la Seguridad Sanitaria de las Personas en la Aplicación Terrestre de Plaguicidas Agrícolas ${ }^{27}$. Conforme al mismo, el trabajador agrícola que esté en contacto con los agrotóxicos

${ }^{25}$ No es objeto de este trabajo abundar sobre la temática sindical, para lo cual remitimos a Thayer Arteaga, William y Novoa Fuenzalida, Patricio, Manual de Derecho del Trabajo (Santiago, Editorial Jurídica de Chile, 1998).

${ }^{26}$ Baraona, Jorge, La culpa de la víctima en los accidentes del trabajo. Dogmática y jurisprudencia chilenas. En BARAONA Jorge y Zelaya, Pedro (editores), La responsabilidad por accidentes del trabajo (Santiago: Cuadernos de Extensión Jurídica-Universidad de los Andes, 2005).

${ }^{27}$ Decreto No 158 publicado el 23 de junio de 2015. 
deberá utilizar los elementos de protección personal indicados en la etiqueta del producto, poseer entrenamiento específico en la utilización del producto y encontrarse en un programa de vigilancia epidemiológica por exposición a agrotóxicos (cfr. Decreto No 158, arts. 6, 17 y 19). Resulta relevante indicar que este reglamento abarca un amplio espectro de agentes químicos utilizados en la agricultura, incluyendo compuestos orgánicos e inorgánicos, sus sustancias activas y las mezclas de éstas ${ }^{28}$.

Asimismo, en el Listado de Enfermedades Profesionales de 2010, en el puesto 1.1.36 se incluyen las enfermedades causadas por plaguicidas como agente tóxico presente en el ámbito laboral.

Esta indicación viene acompañada de algunas políticas públicas que dan cuenta de la toxicidad de estos agentes en el ámbito rural. En primer lugar, desde 1993, el Ministerio de Salud realiza un seguimiento de las intoxicaciones agudas por plaguicidas y las declaró de notificación obligatoria en $2004^{29}$. Por otra parte, el Decreto No 47 de 2016, establece la Política Nacional de Seguridad y Salud en el Trabajo, imponiendo un enfoque preventivo de riesgos laborales ${ }^{30}$. No obstante, no existe hasta el momento un seguimiento de intoxicaciones crónicas $^{31}$, que, como veremos en el apartado siguiente, generan enfermedades que no se encuentran amparadas legalmente.

\section{La percepción de inconsistencias en la tutela de los trabajadores expuestos} a agrotóxicos

La emergencia de ciertas enfermedades en la población laboral agraria ha sido observada no sólo por los científicos, sino y en primer lugar por

${ }^{28}$ Decreto No 158 , art. 2, indica que el significado del término plaguicida incluye a aquel "compuesto químico, orgánico o inorgánico, o sustancia natural, que se utilice para combatir malezas, enfermedades o plagas potencialmente capaces de causar perjuicios en organismos u objetos. Se considerará como tal el producto formulado, las sustancias activas con las que se formulan y las mezclas de éstas, con aptitudes insecticidas, acaricidas, nematicidas, molusquicidas, rodenticidas, lagomorficidas, avicidas, fungicidas, bactericidas, alguicidas, herbicidas, defoliantes, desecantes, fitorreguladores coadyuvantes, antitranspirantes, atrayentes feromonas, repelentes y otros que se empleen en las actividades agricolas y forestales".

${ }^{29}$ Ministerio de Salud (Gobierno de Chile), Norma técnica de vigilancia de intoxicaciones agudas por plaguicidas (Santiago, REVEP, División de Planificación Sanitaria, Departamento de Epidemiología, 2007).

${ }^{30}$ Decreto No 47, publicado el 16 de septiembre de 2016.

${ }^{31}$ Silva, Anamaría - Arancibia, Mariana - Pulgar, Claudio et al., Exposición a plaguicidas y prácticas de uso y protección en embarazadas de zona rurales en control de atención primaria en la región de Valparaiso, Chile en Revista Chilena de Obstetricia y Ginecología 80 (2015) 5, pp. 373-380. 
los propios afectados. La constatación de un aumento del índice de cáncer en trabajadores que manipulan productos agrotóxicos y las limitaciones científicas para verificar un vínculo de causalidad socavaron la convicción de los trabajadores en la ciencia.

Esta desconfianza ha sido conceptualizada a partir de la percepción del riesgo que poseen los ciudadanos. Este elemento del riesgo socialmente producido, manifiesta la existencia del conocimiento por parte de los ciudadanos de la nocividad y potencial dañoso del producto, a pesar que científicamente ello no sea comprobable. Este fenómeno ha sido objeto de investigación de sociólogos y de quienes realizan estudios sobre la ciencia y la tecnología. Algunos autores han focalizado su interés en las formas institucionalizadas en las cuales la ciudadanía "demuestra" el daño ${ }^{32}$. Mientras que otros han profundizado en la aceptabilidad individual del riesgo $^{33}$, relacionándola a conceptos de libertad y justicia pero también a connotaciones culturales.

En el caso que estudiamos, la ciudadanía ha institucionalizado conocimiento a partir de los daños a la salud de poblaciones aledañas a los territorios fumigados ${ }^{34}$, pero los trabajadores rurales, en tanto colectivo de ciudadanos, no han producido este tipo de conocimiento.

La explicación fundada en la asunción involuntaria de riesgos, si bien es útil para dar cuenta de la sensibilidad política de ciertos riesgos, no echa luces acerca de la pasividad del colectivo de trabajadores frente a los mismos riesgos. En este aspecto, Douglas aporta la tesis del filtro institucional de los riesgos, considerando "las funciones que desempeñan las instituciones en la solución de problemas, en la toma de decisiones y en la codificación de información" ${ }^{35}$. En un análisis de este tipo, puede constatarse que los trabajadores agrarios conocen los daños producidos por productos agrotóxicos aunque no pueden categorizarlos como riesgosos. Así lo ha demostrado un estudio de campo realizado por la Secretaría de Ambiente de Argentina, que verificó que el 61,8\% de los encuestados conocía casos de intoxicaciones por agrotóxicos que databan de más de un año ${ }^{36}$. En el

32 JASANOFf, Sheila, Civic Epistemology en JASANOFf, Sheila (coordinadora), Designs on Nature: Science and Democracy in Europe and the United States (Princeton, NJ: Princeton University Press, 2005), pp. 247-271.

${ }_{33}$ Douglas, Mary, La aceptabilidad del riesgo según las ciencias sociales (trad. Víctor Martínez, Barcelona, Paidós, 1996).

${ }^{34}$ Berros, Valeria, Entramado precautorio. Un aporte desde el derecho para la gestión de riesgos ambientales y relativos a la salud humana en Argentina en: Documentos Lascaux. Disponible en: http://www.droit-aliments-terre.eu/documents/ sources_lascaux/articles/2013/MV_Berros_these.pdf [consultado el 20/08/2013]

35 Douglas, cit. (n. 33), p. 143.

36 Secretaría De Ambiente y Desarrollo Sustentable, La problemática de los 
mismo sentido, estudios realizados en Chile dan cuenta del conocimiento que posee la población rural acerca del riesgo de utilización de agrotóxicos, asociando este conocimiento a la experiencia personal de los trabajadores rurales $^{37}$, y a la divulgación realizada desde diversos programas de apoyo campesino ${ }^{38}$.

Asimismo la lectura de algunos testimonios individuales ${ }^{39}$ permite visualizar que los trabajadores perciben el riesgo de la utilización de agrotóxicos a partir de los efectos producidos. En los testimonios se observa que los trabajadores ven limitada su libertad de acción al considerar como única alternativa al desamparo laboral, el trabajo en el ámbito rural. A pesar de ello tienen capacidad cognitiva para dar cuenta de la desprotección en que se encuentran frente a estos riesgos y critican la investigación científica que los ha utilizado como conejillos de India en pos del progreso tecnológico.

En estos testimonios el lugar del otro es ocupado, en algunos casos por las empresas que producen los agrotóxicos (individualizadas como el actor científico que experimenta con ellos) y por los empleadores (que se desentienden de los efectos de su aplicación).

En el caso de Chile se da la particularidad de que la notificación obligatoria al Ministerio de Salud en caso de intoxicación aguda por agrotóxicos (la intoxicación crónica no está prevista), da inicio a una investigación en la cual el trabajador puede perder días laborables sin indemnización y derivar en una posible sanción de la intoxicación ${ }^{40}$. De este modo, la institución estatal coadyuva, colateralmente, al ocultamiento de los efectos sufridos por tal intoxicación.

El discurso se legitima por la alusión al daño sufrido en persona, no hay

agroquimicos y sus envases, su incidencia en la salud de los trabajadores, la población expuesta por el ambiente. Estudio Colaborativo Multicéntrico (Buenos Aires, Secretaría de Ambiente y Desarrollo Sustentable, Organización Panamericana de la Salud, Asociación Argentina de Médicos por el Medio Ambiente, 2007) p. 231.

37 Silva, cit. (n. 31), P. 379.

38 Silva Dreyer, Anamaría - Arancibia Mariana - Arnao Díaz, Maya et al., Exposición a plaguicidas y determinantes sociales de la salud en pequeños agricultores y agricultoras de la V Región Valparaiso, Chile en Revista Cuestiones de Población y Sociedad 7 (2016) 7, Año V, pp. 21-31.

39 En este caso hemos trabajado con los testimonios de Gustavo Barletta, agricultor de Marcos Juárez, publicado en Rulli, Jorge (comp.), Pueblos fumigados. Los efectos de los plaguicidas en las regiones sojeras (Buenos Aires, Del Nuevo Extremo, 2009), p. 146; de niños banderilleros aparecidos, véase Diario La Capital de Rosario (3 de septiembre de 2006) sección La Región; y con el testimonio de un trabajador citado por CеRIOTti, Oscar, Intervención, en III Semana Argentina de la Salud y Seguridad en el Trabajo (2006), Disponible en: http://www.srt.gov.ar/super/eventos/ Semana2006/programa.htm [consultado el 19/04/2009].

${ }^{40}$ Silva, cit. (n. 31), p. 379 y Silva Dreyer, cit. (n. 38), p. 26. 
en general alusión a terceros damnificados en los testimonios. El contexto de producción de estos discursos da cuenta de una finalidad de influir en la sociedad, pues las publicaciones en las cuales están insertos son de divulgación (diarios, libros de divulgación, ponencia en un Congreso).

Por su parte, el sindicato de los trabajadores agrarios argentinos, UATRE (Unión Argentina de Trabajadores Rurales y Estibadores) acepta que la temática de agrotóxicos se vuelve central en los encuentros y cursos de capacitación ${ }^{41}$, aclarando que "no sabemos cuál es el riesgo que tiene, porque se hacen análisis y estudios y no sale que es intoxicado o está el trabajador discapacitado por estos agroquímicos" ${ }^{2}$.

De este modo, las enfermedades profesionales del sector agrario producidas por agrotóxicos se configuran como un producto de la sociedad pos-moderna, tecnológica, en la que la ciencia no tiene elementos para cuantificar el riesgo.

\section{NuEVOS RIESGOS LABORALES CONTEMPLADOS CON VIEJAS}

\section{LENTES}

Antes de adentrarnos en el estudio de la relación causal adoptada en las enfermedades profesionales, haremos una breve disquisición acerca de la naturaleza de los riesgos derivados de agrotóxicos. Parece relevante detenerse en este punto por dos razones: por una parte no se trata de riesgos mensurables, sino de riesgos producidos en el marco de cambios tecnológicos cuya característica es la indeterminación científica; por otra parte, esta particularidad condicionará la relación entre Derecho y Ciencia.

\section{Los riesgos laborales derivados del uso de agrotóxicos y la fragilidad de} la relación ciencia-derecho

Los primeros estudios acerca de los posibles efectos sobre la salud y el medio ambiente del glifosato se remontan a principios de la década de $1980^{43}$. Por su parte, desde los organismos internacionales, la advertencia sobre el riesgo de utilización de estos agrotóxicos sólo se observan desde la década de $1990^{44}$, a partir de la observación de efectos en el medio ambiente

${ }^{41}$ Revista Pregón Rural, edición digital, disponible en: http://www.uatre.org.ar/ pdf julio/nota\%2010.pdf [consultado el 2/03/2011].

${ }^{42}$ Ceriotti, cit. (n. 29) s/p.

43 NiviA, Elsa, Efectos sobre la salud y el ambiente de herbicidas que contienen glifosato, (2000). Disponible en http://www.rel-uita.org/Agrotoxicos, [consultado el 15/07/2009].

${ }^{44}$ Por ejemplo, a través del Proyecto de cooperación técnica sobre seguridad y salud en la agricultura, que se llevó a cabo en América Central de 1993 a 1998 por la OIT, 
a corto plazo (extinción de especies animales y vegetales, contaminación de las napas de agua, etc.) insinuándose que los efectos en los seres humanos se observarían sólo a largo plazo.

A esta indeterminación temporal de los daños, se suma una incerteza científica, plasmada en diversas investigaciones que arrojan resultados también discrepantes acerca del efecto de los agrotóxicos sobre el ambiente y la salud humana. Nos encontramos, en este caso, ante un riesgo que difícilmente pueda ser gestionado a través del paradigma de racionalidad de las ciencias, pues los parámetros de causalidad en los que se basa, escapan a los postulados de la ciencia moderna ${ }^{45}$, cuya técnica no puede operar en riesgos no cuantificables y accidentes improbables.

Durante la modernidad industrial el Derecho le otorgó a la ciencia el papel esencial de desentrañar las causas desencadenantes de daños. Esta relación de causalidad demostrada por la ciencia se legitimaba en el paradigma de la observación objetiva y la verificación de los mismos efectos para idénticas causas. Pero el método científico positivista se estremece ante la verificación causal en este tipo de daños, por la imposibilidad de una observación objetiva que sea demostrable en laboratorios y fuera de ellos ${ }^{46}$.

Esta distribución de roles ha sido descripta como una "entrega de la decisión" por parte del derecho a la ciencia. Así puede observarse que de diversas maneras, la decisión acerca de la calificación del daño como enfermedad profesional es dirimida desde el estamento científico. Ello opera no sólo a partir de conceptos existentes en las propias leyes laborales (en este caso el listado de enfermedades profesionales de la ley argentina se realizó en base a categorías conceptuales que provienen de las ciencias de la salud) sino también a partir de una "remisión a lo que el estado de la ciencia y la técnica disponga en cada caso" ${ }^{37}$.

o publicaciones de estos organismos como FAO, Guidelines for Personal Protection when working with pesticidas in tropical climates, (Disponible en: http://www.fao. org/ag/agp/agpp/pesticid/code/download/protect.doc [consultado el 27/07/2009], 1990) entre otros.

${ }^{45}$ La pretensión de racionalidad de las ciencias formulada a partir del Siglo XIX pretendía prevenir los riesgos de la experimentación generalizada a partir de la comprobación de la relación causa-efecto. Hermitte Marie-Angèle, La fundación jurídica de una sociedad de las ciencias y de la técnica a través de las crisis y de los riesgos, en DiAs Varella, Marcelo, Derecho, Sociedad y Riesgos. La Sociedad Contemporánea vista a través de la idea de riesgo (Brasilia, Centro Universitário de Brasilia, 2007), pp. 13-64.

${ }^{46}$ Por ejemplo, los experimentos son realizados sobre animales, sin tomar en cuenta que en humanos el cóctel de productos químicos que pueden estar en juego es diferente y se critica el cálculo de los valores 'tolerables' que no toman en cuenta los extremos de exposición.

47 Esteve Pardo, José, El desconcierto del Leviatán. Política y derecho ante las 
En este último sentido, a partir de la lectura de tres publicaciones de la Organización Internacional del Trabajo (OIT en adelante) es posible visualizar la modificación del discurso acerca de los riesgos de los trabajadores rurales en virtud de mudanzas en el estado de las investigaciones científicas. El análisis del discurso contenido en estas publicaciones se realiza a fin de ilustrar la variación científica acerca de la consideración de los efectos de los agrotóxicos en los trabajadores agrarios. El mismo no representa un análisis exhaustivo ni representativo de los diferentes estadios de la ciencia. La finalidad es remarcar en el discurso de una organización internacional la relación entre la ciencia y los sistemas regulatorios de las enfermedades laborales.

Así, en 1996 se advertía que "en los países en desarrollo los trabajadores más expuestos a riesgos de carácter profesional son los ocupados en la agricultura, las industrias primarias de extracción y la industria pesada. La deficiente calidad del equipo, el volumen excesivo de trabajo, e incluso la intoxicación por pesticidas o polvos orgánicos menoscaban gravemente la salud y la seguridad de los trabajadores”48. En esta transcripción la OIT se refiere a un supuesto conjetural en tanto no menciona los riesgos sufridos sino los riesgos a los que se ven expuestos los trabajadores. De esta manera, existe una primera barrera para advertir en este párrafo una observación de supuestos empíricos de riesgos sufridos. Por otra parte, de la lectura surgen dos agrupaciones, por una parte los sujetos expuestos a riesgos y por otra los factores desencadenantes. En el primer caso se nombran los trabajadores de agricultura junto a aquellos de industrias primarias de extracción y de industria pesada. Esta asociación va en detrimento de especificar riesgos particulares de los trabajadores agrarios, justificando una mención de factores desencadenantes propios de la sociedad industrial. En segundo término, al mencionar la intoxicación por pesticidas junto a riesgos gobernados a través del dispositivo del seguro lo hace utilizando el adverbio "incluso", que indica una situación u objeto no esperado en la sucesión. De este modo es destacable la mención de este tipo de riesgos que encierran una incertidumbre científica junto a otros (como la calidad del equipo o el volumen de trabajo) que pueden ser gobernados por la técnica de cálculo actuarial. Esta mención conjunta puede asociarse a una débil verificación científica de la incidencia de tales riesgos. Así, este

incertidumbres de la ciencia (Madrid, Marcial Pons, 2009), P. 18.

${ }^{48}$ Organización Internacional del Trabajo, Aumentan los riesgos para la seguridad y la salud de los trabajadores, advierte la OIT en Comunicado de Prensa, 22/04/1996, Ref. OIT/96/13. Disponible en: http://www.ilo.org/global/About_the_ILO/Media_and_public_information/Press_releases/lang--es/WCMS_008410/index.htm [consultado el 19/09/2009] 
fragmento puede ser ilustrativo de una etapa incipiente en el desarrollo de investigaciones sobre riesgos por agrotóxicos.

En otro documento, de 1997, observa que "los mayores peligros para los trabajadores agrícolas provienen de las herramientas cortantes y la maquinaria. (...) Los deficientes sistemas nacionales de estadística hacen que los casos registrados de envenenamiento por pesticidas sean mucho menores que los reales" ${ }^{\text {"99. }}$. En este caso la OIT se refiere específicamente a los trabajadores agrarios, mencionando en la cita dos tipos de riesgos: aquellos provenientes de maquinaria y los resultantes de la manipulación de agrotóxicos. Nuevamente se refiere a exposición a riesgos, aunque posibilita la pauta de daños sufridos al mencionar los sistemas nacionales de estadística. La conclusión del documento se centra en una proliferación de riesgos provenientes de la sociedad industrial, no pudiendo mensurar aquellos surgidos en la sociedad del riesgo, debido, según la Organización, a deficientes sistemas de estadísticas. De ello se deduce que este extracto no da cuenta de las dificultades de registrar y mensurar este tipo de riesgos. En este caso, si bien puede entreverse una observación científica del envenenamiento por pesticidas, la misma no se traduce aún en dispositivos legales que permitan su registro. Se ilustra, así, un estadio posterior en la investigación científica que sólo es acompañado dilatadamente por el derecho.

Finalmente, en el año 2000, en un documento dedicado a la seguridad en la agricultura se señala que "la exposición a plaguicidas y otros productos agroquímicos constituye uno de los principales riesgos profesionales. Estos provocan intoxicación y muerte, y en algunos casos, cáncer profesional y trastornos de la función reproductora. (...) Las enfermedades crónicas causadas por (...) una baja exposición a polvos orgánicos o a plaguicidas son más difíciles de evaluar debido a sus efectos a largo plazo y a sus sín-

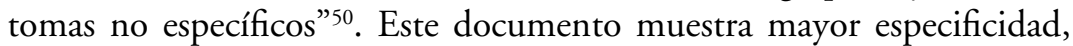
puesto que no sólo se refiere particularmente al sector agrícola, sino que menciona los efectos de la exposición al factor de riesgo. Puede observarse, asimismo, una aceptación de las limitaciones de la ciencia moderna para dar cuenta de los efectos de los agrotóxicos sobre la salud humana. En el

${ }^{49}$ Organización Internacional del Trabajo, Nuevo informe sobre la seguridad en la agricultura. Advertencia a los trabajadores agricolas: los indices de mortalidad siguen siendo elevados y los pesticidas suponen un riesgo creciente para la salud en Revista Trabajo de la OIT, 22 (diciembre de 1997), disponible en: http://www.ilo.org/public/ spanish/bureau/inf/magazine/22/22farm.htm, [consultado el 25/05/2013].

${ }^{50}$ Organización Internacional del Trabajo, Seguridad y Salud en la Agricultura, en SafeWork (junio de 2000), disponible en: http://www.ilo.org/public/english/ protection/safework/agriculture/brochure/spanish/agricult_s.pdf [consultado el 25/05/2013]. 
texto, ello se justifica en la dificultad de evaluar efectos a largo plazo de los productos tecnológicos generados. Esta descripción concuerda con la de riesgo producido socialmente, o riesgo de la sociedad global: el mismo es incontrolable con las técnicas de la sociedad industrial y representa una posibilidad de daño incalculable para los científicos. Es, en síntesis, algo que no conocemos, incierto y que genera, a la par del peligro de un daño cierto, una desconfianza y temor por parte de los involucrados que no puede ser dominada por los científicos. En este texto se visualiza un avance científico respecto de los precedentes, incluso en la reflexividad acerca de las posibilidades de conocimiento del riesgo, a la cual se repliega la regulación.

Teniendo en cuenta que las transformaciones jurídicas "se desenvuelven en el cuadro de la explicación científica del mundo" 51 , jurídicamente ello se traduce en una insuficiencia de las herramientas clásicas para indemnizar los daños causados. De esta manera, el control del reconocimiento de estos riesgos se realiza a través de la oclusión de la relación de causalidad. Cuanta más inmediatez se exige en la relación causal, más se estrecha el círculo de los riesgos reconocidos y mayor es el mar de los no reconocidos. En la decisión acerca de la relación causal, el discurso político juega un papel esencial, por ello Beck atiende a la relación entre la racionalidad científica y la racionalidad social ${ }^{52}$.

\section{Teorias jurídicas del presupuesto relación causal}

En el caso de las enfermedades profesionales, la relación causal no es manifiesta, sino que es establecida por el Poder Ejecutivo al elaborar la lista referida, y posteriormente sólo se tienen en cuenta aquellas enfermedades incluidas en la lista. A partir del análisis de las distintas doctrinas que se han desarrollado en el ámbito del derecho civil, para explicar y fundamentar la relación de causalidad como presupuesto de la responsabilidad, revisaremos de qué manera se traducen algunas de ellas en la LRT y en la LATEP y qué efectos traen aparejados.

El art. 6 inc. 2 de la LRT, al tratar del ámbito de aplicación a las enfermedades profesionales, delega en el Poder Ejecutivo la elaboración de una nómina de enfermedades que serán consideradas profesionales. Además de ellas, existe la posibilidad de incluir otras enfermedades en el ámbito de aplicación de la ley, a través del procedimiento reglado en el art. 6 inc. 2 b).

Conforme la LRT, el listado debe identificar "agente de riesgo, cuadros clínicos, exposición y actividades en capacidad de determinar la enfermedad profesional'. La aprobación del listado de enfermedades laborales realizada

51 Hermitte, cit. (n. 45), P. 15.

52 BECK, cit. (n. 4), P. 34. 
por Decreto del Poder Ejecutivo Nacional, tuvo como fuente material, entre otras, el laudo del Ministerio de Trabajo y Seguridad Social no 156 de 1996, el cual posee un preámbulo que se torna relevante para nuestro estudio. Un examen del mismo permite observar la tendencia que incorpora el mismo en relación a este tema.

El preámbulo del laudo establece que serán enfermedades profesionales "aquellas que son el resultado directo del trabajo que realiza una persona". Más adelante, instituye criterios para diferenciar una enfermedad laboral de otro tipo de enfermedades, entre los cuales están: el agente (debe existir en el ámbito laboral), exposición (el contacto con dicho agente debe ser suficiente para provocar la enfermedad), enfermedad y relación causal entre la aparición de estos elementos entre sí.

A primera vista, pareciera que la ley toma como criterio la teoría de la causalidad adecuada. Esta doctrina fundamenta la existencia de una relación causal siempre que la acción sea "idónea para producir el resultado acaecido, o sea, debe acarrearlo normalmente" 53 . Las críticas relativas al criterio por el cual se realizaba el juicio de probabilidad y aquellas referentes a la actuación de expertos produjeron la mutación hacia la enunciación de la concausa. Ello ocurrió al explicitar que la regularidad exista en cada etapa de la serie causal.

El listado, al relacionar el agente de riesgo con la exposición al mismo y el cuadro clínico (de modo de advertir si este último es resultado normal de la exposición al agente de riesgo) cumplimenta la primera enunciación de la doctrina de la causalidad adecuada. Por otro lado al tener en cuenta las actividades que pueden normalmente determinar dicha enfermedad completa la regularidad en toda la serie causal.

Sin embargo, al observar el listado aprobado, advertimos que dicha teoría no es pertinente para explicar la relación causal tenida en cuenta.

La teoría de la causalidad eficiente, elaborada posteriormente, entendía que la causa era "aquella que tiene un intrínseco poder de producción del fenómeno" ${ }^{4}$. No obstante, el problema en la aplicación de esta doctrina radica en obtener una pauta objetiva que permita establecer cuál de todas las causas que han colaborado en el origen del daño fue la determinante. Esta pauta variará históricamente según el estado de la investigación científica.

Para el caso estudiado es necesario acotar que en el ámbito de la medicina, es ampliamente reconocido que en la génesis causal de una enfermedad, pueden distinguirse causas desencadenantes del proceso morboso y

53 BRebBia, Roberto, La relación de causalidad en derecho civil (Rosario, Juris, 1975) p. 40.

${ }^{54}$ Brebila, cit. (n. 53) p. 33. 
causas predisponentes, el conjunto de las cuales se denomina "constelación causal" 55 . Según esta concepción, es necesario hacer estudios estadísticos sobre la presencia de unos factores frente a otros y la aparición de la enfermedad, para poder llegar a la verdadera causa de la misma. Además de los estudios médicos, es una noción de sentido común que el organismo como un todo, no reacciona aisladamente a los agentes hostiles que se encuentran en el ámbito familiar, social y laboral.

Estas consideraciones permiten colegir que la posición que tomó el Comité Consultivo Permanente al elaborar el listado de enfermedades fue restrictiva. Esta afirmación se apoya en el propio texto del preámbulo, que demostró que dicha multicausalidad formaba parte del estado de la ciencia en ese momento ${ }^{56}$.

El listado adopta un criterio amplio para incorporar los agentes, y la inclusión de enfermedades se hace por la "existencia de un cuadro clínico definido que se relacione con un agente determinado". La relación de causalidad entre el agente y la enfermedad es expuesta con carácter restrictivo. De hecho, textualmente dice el preámbulo examinado "la relación de causalidad es el componente que exige los parámetros más estrictos para establecerla”. Estos parámetros se desarrollan por la demostración de una alteración bioquímica, funcional o anatómica característica del agente que la produce y a través de estudios epidemiológicos que permitan identificar las enfermedades más frecuentes en algunos grupos ocupacionales. Como se puede observar, estos dos requisitos (demostración de una alteración orgánica y estudios epidemiológicos), son inexistentes en el caso de las enfermedades derivadas de agrotóxicos.

También se observa el criterio restrictivo cuando menciona que "los análisis estadísticos que demuestren una asociación positiva entre el trabajo y la patología estudiada deben estar exentos de sesgos que resten validez a las conclusiones", o cuando establece que "hay otras enfermedades transmisibles ocupacionales que se han incorporado a la lista porque se reconoce que el modo de transmisión es específico a ciertas ocupaciones" $y$, finalmente, cuando manifiesta que "el establecimiento de listas de enfermedades profesionales expresa la voluntad de restringir el reconocimiento de ellas a las que cumplen con determinadas condiciones que a priori han sido evaluadas para ese efecto".

55 Barahona, Roberto (compilador), Manual de Patología General. Disponible en http://escuela.med.puc.cl/publ/PatologiaGeneral/Patol_001.html, [consultado el 17/07/2007].

${ }^{56}$ El propio preámbulo define: "Multicausalidad: una misma enfermedad puede tener distintas causas o factores laborales y extralaborales que actúan al mismo tiempo y que contribuye a su desencadenamiento". 
Finalmente, al hacer referencia al patrón de listado tomado como base (lista aprobada por la OIT en 1994), aclara que "esta lista incluye algunos agentes químicos, en particular, para los cuales no existe una patología claramente definida, a excepción de los efectos agudos irritativos, que no serán incluidos en esta proposición de lista”.

A partir del análisis de esta extracción de párrafos del preámbulo del laudo, podemos concluir que el criterio con el cual se ha aprobado el listado de enfermedades profesionales es sumamente restrictivo respecto al presupuesto de la relación de causalidad.

De esta manera, se deja sin resguardo no sólo a aquellos trabajadores que tienen predisposición a contraer ciertas afecciones (predisposición que es activada por agentes presentes en el ámbito laboral) sino también a aquellos trabajadores que, en contacto directo con agentes hostiles presentes no sólo en el ámbito laboral sino en otros espacios, adquieren enfermedades profesionales.

La restricción opera, asimismo, en el ámbito de las consecuencias por las cuales se responde. La LRT establece la responsabilidad en el ámbito de las enfermedades profesionales sólo por aquellas que son consecuencia inmediata de los agentes patógenos presentes en el ámbito laboral. Esta circunscripción evita que puedan considerarse como enfermedades profesionales aquellas que son consecuencia mediata del agente laboral, pero previsible.

De hecho, al observar el listado aprobado, advertimos que sólo consta de dos columnas: enfermedades (cuadro clínico en la redacción de la ley) y actividades laborales que pueden generar exposición, estableciéndose una relación directa entre los agentes riesgosos y las enfermedades descriptas. Los expertos han criticado esta disposición, pues ni siquiera las enfermedades que son causa directa del agente riesgoso están incluidas dentro de la distribución realizada ${ }^{57}$.

En resumen, la legislación argentina adopta la teoría jurídica de la causalidad eficiente para relacionar agente de riesgo con enfermedades

57 Señala Miraya, Federico, Análisis de la legislación sobre ruido y vibraciones Disponible en : http://www.eie.fceia.unr.edu.ar/-acustica/biblio/legis.pdf [consultado el 20/08/2007]: "En el caso específico del ruido, por ejemplo, se dejan afuera multitud de dolencias que son ocasionadas por el ruido (aunque no únicamente por dicho agente). Por ejemplo, se considera que algunas enfermedades profesionales del aparato fonatorio, como algunos tipos de disfonías, están originadas por el agente 'Sobrecarga del uso de la voz', sin tener en cuenta que en muchos casos dicha sobrecarga es en realidad consecuencia del ruido, debido al reflejo cócleorrecurrencial (que hace aumentar la tensión en las cuerdas vocales en presencia de niveles elevados de ruido)". 
profesionales acaecidas. Como se mencionó antes, el problema de esta teoría es determinar cuál de todas las causas tuvo un intrínseco poder de causación. No obstante, para el instituto de enfermedades profesionales, dicha dificultad se salva cuando cierra el sistema a toda enfermedad cuya concausa incluya fenómenos (patologías) que están fuera del ámbito laboral. La ley quiere que la enfermedad no reconozca sino una causa única: el trabajo.

Por su parte, la LATEP, en su artículo 7 encomienda al Poder Ejecutivo, a través de un Reglamento, la enumeración de las enfermedades profesionales. Ello se realizó mediante Decreto No 109 de 1968, que aprobó el Reglamento para la calificación y evaluación de enfermedades profesionales. Conforme este Decreto, el listado de enfermedades profesionales es flexible, siendo revisado, al menos, cada tres años.

Por otra parte, el artículo 7, inciso 3 de la LATEP establece la posibilidad de otorgar cobertura a enfermedades no incluidas en el listado, a partir de un procedimiento que debe iniciar el afectado. Mediante el mismo, el trabajador "debe solicitar que se le practiquen exámenes para estudiar la eventual existencia de una enfermedad profesional, en caso que existan o hayan existido en el lugar de trabajo, agentes y/o factores de riesgo que pudieran asociarse a esa enfermedad'. Este procedimiento se realiza ante el organismo administrador respectivo (esto es, ante el organismo asegurador), y reconoce la enfermedad como laboral sólo en caso de que la misma fuese consecuencia directa del trabajo y existan agentes específicos que determinen el riesgo de la misma ${ }^{58}$.

Sierra y Nasser consideran que la definición establecida por la LATEP da cuenta de una causalidad directa en la determinación de la enfermedad profesional ${ }^{59}$. Para ello resaltan que el Decreto No 109 alude a "trabajos que entrañan el riesgo respectivo" (art. 16, Decreto No 109) distinguiendo, de este modo, las enfermedades profesionales de aquellas enfermedades comunes, por medio de un criterio "objetivo". Asimismo, esta norma relaciona los "agentes específicos", agrupados en categorías, con las diversas actividades laborales (art. 18, Decreto No 109).

De modo similar al listado argentino, en Chile la regulación "señala cómo y cuándo dichos agentes específicos pueden conectarse de manera causal y física con los trabajos que 'entrañan el riesgo respectivo"'60. Ello implica que, en los casos en que el trabajador posea una predisposición

58 SIERRA, Alfredo y NASSER, Marcelo, La responsabilidad del empleador por enfermedades profesionales de sus trabajadores. Enfoque jurisprudencial en Revista Chilena de Derecho, 39 (2012) 1 pp. 57-76.

59 Sierra y NASSER, cit. (n. 58), p. 59.

${ }^{60}$ Sierra y NASSER, cit. (n. 58), p. 60. 
a contraer cierta enfermedad profesional, no pueda reclamarse cobertura por la misma.

El momento inicial a partir del cual se puede comenzar a contar el plazo de prescripción de la acción para reclamar prestaciones conforme la LATEP configura una disposición particular. Dicho plazo comienza desde que la enfermedad ha sido diagnosticada por las entidades aseguradoras, siendo, asimismo, de distinta extensión en algunas enfermedades (cfr. Art. 79 LATEP). Ello permite que el trabajador pueda, por una parte, reclamar las prestaciones de la seguridad social ante enfermedades que se manifiestan posteriormente a la extinción de la relación laboral. Por otra parte, el trabajador afectado puede iniciar la acción de responsabilidad contra el empleador por incumplimiento del deber de seguridad. Esta flexibilidad en el inicio de plazo de prescripción opera favorablemente en casos como el estudiado, en los cuales las consecuencias del riesgo se manifiestan tiempo después de la exposición al agente causal, debido a que la intoxicación que se ha producido es crónica. No obstante, en esta circunstancia, la valoración de la prueba de la relación causal entre los factores de riesgo y la enfermedad se presenta de modo más riguroso, obligando "a un análisis muy estricto a la hora de imputar responsabilidades" 61 .

Del análisis realizado se desprende que en ambas legislaciones la relación causal se basa en la teoría de la causalidad eficiente. Conforme la misma, se considera que el trabajador afectado tendrá cobertura legal en los casos en que el trabajo, o la ocupación, sean intrínsecamente los productores de la enfermedad laboral. Para ello, se considera como un elemento objetivo, que permite determinar si las tareas produjeron la enfermedad del trabajador, la exposición a ciertos agentes causales que están determinados previamente en un listado elaborado por el Poder Ejecutivo. Fuera de este listado es posible, en ambos países, que el trabajador acredite que la enfermedad que padece fue generada por causas laborales. No obstante, esta acreditación es rigurosa en la valoración de la prueba y exige justificar que la enfermedad es un efecto directo de las labores realizadas.

En el caso bajo estudio concurren un conjunto de elementos que hacen inoperable esta relación causal y dejan al trabajador afectado sin cobertura frente al riesgo creado. Entre ellos, podemos mencionar que las enfermedades producidas por agrotóxicos son variadas, y sus síntomas se presentan similares a los de otras patologías ${ }^{62}$; por otra parte, ello se imbrica

${ }^{61}$ Sierra y Nasser, cit. (n. 58), p. 74.

${ }^{62}$ En algunas investigaciones se indica que entre estos síntomas aparecen las cefaleas, las molestias gástricas y los síntomas dermatológicos. Los trabajadores que han sufrido estos síntomas los relacionan con el contacto con agrotóxicos, no obstante, los consideran como parte del trabajo, "un mal necesario", y frente a éstos proceden 
en con la controversia científica existente acerca de su causalidad. En estas circunstancias, parece necesario revisar los medios probatorios para esta situación, la relación de causalidad exigida y, en última instancia, el deber de seguridad que pesa sobre el empleador.

\section{Repensando el deber de seguridad ante los nuevos riesgos laborales}

Cuando este sistema jurídico intenta aplicarse a patologías como las provenientes de la exposición a agrotóxicos, podemos verificar un desfasaje respecto de las relaciones causales del sistema y de la enfermedad. Esto conlleva la no recepción de estas patologías por el sistema y, consecuentemente, una desprotección de los trabajadores rurales ante este riesgo.

Se advierte, en este caso una ineficacia de la teorización de la relación causal para abarcar este tipo de problemáticas, relacionadas a la generación de nuevos riesgos por la sociedad pos industrial.

La figura de la responsabilidad objetiva, basada en una causalidad adecuada, era aceptable para una sociedad en la cual las actividades de los individuos se desenvolvían de acuerdo a riesgos calculables (aunque evidentemente no aceptables). Esta previsión se realizaba a través de cálculos actuariales que establecían probabilidades de riesgo para ciertos grupos sociales, es decir que tomaba en cuenta el carácter colectivo de estos riesgos. Para ello, el derecho respondió con la técnica de la causalidad adecuada y estableció formas de reparación de acuerdo a los daños sufridos (forfatarios).

Conforme la descripción de la sociedad actual como una sociedad del riesgo, algunas características deben ser tenidas en cuenta al momento de diseñar dispositivos de regulación: i) el contexto de incerteza científica, con la posibilidad eventual de daños graves o irreversibles; ii) a ello se suman situaciones que escapan a la lógica actuarial (por cuanto no ofrecen las notas de regularidad que requiere la estadística); iii) finalmente los daños pueden afectar a trabajadores como a ciudadanos vecinos a los territorios expuestos a agrotóxicos, e incluyendo daños a la salud como al ambiente, cuya valuación económica es imposible de determinar. Estas características exigen tener a la vista nuevas teorizaciones para aportar al debate regulatorio.

La propuesta de Da Silva Lemos de recurrir a un 'microderecho' que se valdría de nuevos paradigmas racionales para regular las relaciones de la pos- modernidad, nos ofrece una pista para intentar una propuesta a la regulación de estos riesgos ${ }^{63}$. En este sentido, algunos autores han propuesto

descansando un rato o bebiendo agua. Véase Silva, cit. (n. 31), p. 378 y Silva DreYER, cit. (n. 38), p. 24.

${ }^{63}$ Da Silva Lemos, Antônio, El derecho como regulador de la sociedad de riesgos, en Dias Varella, Marcelo, Derecho, Sociedad y Riesgos. La Sociedad Contemporánea 
utilizar nuevas teorías de la relación causal. Néstor Cafferatta en el ámbito de la responsabilidad civil por daños ambientales, enumera una serie de teorías que tratan de repensar la relación causal a partir de dos ejes fundamentales: la posibilidad de que los efectos nocivos de un agente contaminante se manifiesten a largo plazo y la propagación de efectos perniciosos a través de grandes distancias. Refiere a la teoría alemana de la condición peligrosa "que predica que si la acción u omisión crea un peligro capaz de provocar el suceso dañoso, tal acción u omisión puede considerarse como causa eficiente del daño efectivamente ocurrido, según una valoración ex post" ${ }^{\prime 6}$. Esta situación implica no sólo que el Derecho del Trabajo debe adecuar los presupuestos de esta teoría a la especial responsabilidad de los empleadores, sino que los mismos deberán utilizar todos los elementos de seguridad disponibles en el mercado a fin de resguardar la salud de los trabajadores para eximirse de responsabilidad.

Otros autores, en el ámbito de la responsabilidad civil hacen referencia a una causalidad indeterminada, así "la causalidad indeterminada se inserta en el sistema de responsabilidad civil como un tercer sector entre los dos sectores que clásicamente tenía el sistema del derecho de daños, esto es, el sector en el cual podía establecerse una causalidad (sea cual fuere: adecuada, anónima, etc.), es decir, de lo previsible y el campo de lo desconocido, de lo imprevisible e inevitable, gobernado por el caso fortuito y la fuerza mayor. En otras palabras: existe una zona de la causalidad, una zona del caso fortuito y una zona de lo indeterminado" 65 . Este tipo de razonamiento implica la puesta en marcha de investigaciones que pongan a disposición de los afectados los recursos necesarios.

De los autores reseñados podemos extraer una exigencia de re-pensar los fundamentos de la responsabilidad patronal por accidentes y enfermedades laborales. Nuevas teorías basadas en dar cuenta de estos riesgos con otro paradigma, en el cual sean elementos relevantes la imprevisibilidad de los mismos y sus efectos a largo plazo deben surgir para posibilitar guardar la indemnidad de los trabajadores.

vista a través de la idea de riesgo (Brasilia, Centro Universitário de Brasilia, 2007), pp. 367-390.

${ }^{64}$ Cafferatta, Nestor, Perspectivas sobre derecho ambiental y de la sustentabilidad (Salta, Editorial de la Universidad Católica de Salta, 2007), II, p. 22.

${ }^{65}$ Sozzo, Gonzalo, La prevención del daño (ensayo desde la mirada de las vías periféricas), en Revista de Derecho Privado y Comunitario 2 (2008), p. 231. 


\section{CONCLUSIONES}

Los riesgos surgidos por el hecho o en ocasión del trabajo fueron tempranamente percibidos por el Derecho, que reguló su prevención y reparación con modelos de responsabilidad entonces novedosos, como la imputación objetiva. A través de los mismos se buscó la mayor protección de los trabajadores, sujetos frágiles de la relación laboral.

La tecnología de la sociedad industrial moderna creó riesgos que se presentaron, en una primera instancia, como efectos colaterales. No obstante, luego de algunos hechos desencadenantes (particularmente accidentes ambientales y químicos), esta percepción fue modificada. Ciertas actividades que contaban, entre sus efectos colaterales, con la contaminación ambiental o con el peligro de catástrofes imprevisibles, fueron censuradas por la sociedad; y el Derecho creó, alrededor de las mismas, sistemas regulatorios cada vez más complejos que intentan proteger a las personas contra estos riesgos.

En el ámbito del derecho laboral, estos riesgos también están presentes. En el caso estudiado, la incidencia del uso de productos agrotóxicos en la salud de los trabajadores, manifiesta la presencia de una sociedad del riesgo. En la misma, se dan cita algunas características principales que merecen ser destacadas: incertidumbre y controversia científica, no percepción social del riesgo, irresponsabilidad empresaria e insuficiencia de las herramientas jurídicas existentes para lograr su reparación o prevención.

En principio, el deber de seguridad caracterizado como elemento esencial del contrato de trabajo debería ser suficiente para garantizar la indemnidad de los trabajadores. No obstante, su institucionalización en las leyes de riesgos laborales argentina y chilena ha imposibilitado subsumir en sus normas las enfermedades profesionales derivadas del uso de agrotóxicos.

La dificultad no proviene solamente de la técnica legislativa utilizada, sino de las particulares características que distinguen los riesgos sociales, de otros riesgos previsibles, mensurables y de consecuencias limitadas. Jurídicamente, la cuestión radica en la relación de causalidad adoptada por el sistema de protección de las enfermedades profesionales. La misma es una relación de causalidad eficiente, que justifica el no reconocimiento de este tipo de riesgos. En verdad, al elevar el criterio de validez de la demostración de causalidad en los nuevos riesgos de la sociedad post-industrial, constriñe el círculo de riesgos reconocidos y amplía el universo de los no reconocidos.

En el modelo de responsabilidad objetiva, la traducción que realiza el juez acerca de la relación causal no puede englobar un efecto originado por fuentes controvertidas en el ámbito científico, pues la responsabilidad 
por riesgo creado descansa en la racionalidad científica que verificó que la cosa era riesgosa.

Esta verificación sacude los fundamentos del derecho del trabajo, pues implica que hay daños ocurridos por el hecho o en ocasión del trabajo para los cuales el Derecho no tiene reparación. Y ello involucra una afirmación moral: el trabajador, parte débil en la relación laboral, sufre daños en su salud que no pueden ser prevenidos en cuanto no son percibidos como tales; y no pueden ser reparados pues las herramientas jurídicas que deberían servir para ponerlo en igualdad de condiciones respecto del empleador son insuficientes.

Ante ello, nuevas formas de visualizar el problema de la relación causal aparecen en el horizonte. Pensadas originalmente para el derecho civil, es necesario trasladarlas a los presupuestos del derecho del trabajo y elaborar nuevamente sus fundamentos. Quizás, estos nuevos riesgos, incalculables, controvertidos y colaterales no deban ser atribuidos exclusivamente al empleador, que probablemente se encuentre en la misma situación cognoscitiva que los trabajadores. Quizás haya que encontrar nuevos responsables de estos riesgos, que serían quienes verdaderamente se benefician de su producción y de la utilización masiva de estos productos. Quizás las empresas que producen agrotóxicos deberían, si no garantizar la inocuidad de sus productos mediante procesos rigurosos de testeo, cargar con los daños ocasionados a los trabajadores por los mismos.

Los trabajadores están afectados por los riesgos, los mismos son “asignados civilizatoriamente" 66 y esta asignación no es disruptiva de la situación de clases en que se gestaron. Por ello, el Derecho del Trabajo debe renovar su función tuitiva. La tutela frente a los riesgos generados por el nivel más avanzado del desarrollo de las fuerzas productivas requiere repensar los fundamentos de la responsabilidad por riesgos profesionales y ofrecer a los trabajadores una reparación integral y justa a los daños sufridos por el hecho o en ocasión del trabajo.

\section{BiBLIOGRAFÍA}

Ackerman Mario E. (Dir.), Tosca, Diego (Coord.), Tratado de Derecho del Trabajo (Tomo VI, Santa Fe, Rubinzal Culzoni, 2007).

Barahona, Roberto (compilador), Manual de Patología General. Disponible en http://escuela.med.puc.cl/publ/PatologiaGeneral/Patol 001.html [consultado el 17/07/2007]

Baraona, Jorge, La culpa de la víctima en los accidentes del trabajo. Dogmática y jurisprudencia chilenas. En BaraOna Jorge - Zelaya Pedro (edit.), La responsabilidad

${ }^{66}$ BeCK, cit. (n. 4) p. 29. 
por accidentes del trabajo (Santiago: Cuadernos de Extensión Jurídica-Universidad de los Andes, 2005).

BeCK, Ulrich, La sociedad del riesgo global (trad. Jesús Alborés Rey, Madrid, Siglo Veintiuno, 2002).

BECK, Ulrich, La sociedad del riesgo. Hacia una nueva modernidad (trad. Jorge Navarro, Daniel Jiménez - Ma Rosa Borrás, Buenos Aires, Paidós, 1998).

Berros, Valeria; Entramado precautorio. Un aporte desde el derecho para la gestión de riesgos ambientales y relativos a la salud humana en Argentina, en: Documentos Lascaux. Disponible en: http://www.droit-aliments-terre.eu/documents/sources lascaux/articles/2013/MV Berros these.pdf [consultado el 20/08/2013]

BREBBia, Roberto, La relación de causalidad en derecho civil (Rosario, Juris, 1975).

Cafferatta, Nestor, Perspectivas sobre derecho ambiental y de la sustentabilidad (Salta, EUCASA, 2007), II.

CASTEL, Robert, El ascenso de las incertidumbres. Trabajo, protecciones, estatuto del individuo ( $2^{\mathrm{a}}$ ed., trad. Víctor Goldstein, Buenos Aires, Fondo de Cultura Económica, 2012).

Ceriotti, Oscar, Intervención, en III Semana Argentina de la Saludy Seguridad en el Trabajo (2006), Disponible en: http://www.srt.gov.ar/super/eventos/Semana2006/ programa.htm [consultado el 19/04/2009].

Chelala, César, Un reto constante: los plaguicidas y su efecto sobre la salud y el medio ambiente (Washington, Organización Panamericana de la Salud, 2004).

Da Silva Lemos, Antônio, El derecho como regulador de la sociedad de riesgos en DiAS VArella, Marcelo, Derecho, Sociedad y Riesgos. La Sociedad Contemporánea vista a través de la idea de riesgo (Brasilia, Centro Universitário de Brasília, 2007), pp. 367-390.

Douglas, Mary, La aceptabilidad del riesgo según las ciencias sociales (trad. Víctor Martínez, Barcelona, Paidós, 1996).

Esteve Pardo, José, El desconcierto del Leviatán. Politica y derecho ante las incertidumbres de la ciencia (Madrid, Marcial Pons, 2009).

HAIDAR, Victoria, Trabajadores en riesgo. Una sociología histórica de la biopolítica de la población asalariada en Argentina (1890-1915) (Buenos Aires, Prometeo, 2008).

Hermitte Marie-Angèle, La fundación jurídica de una sociedad de las ciencias y de la técnica a través de las crisis y de los riesgos en Dias VARELLA, Marcelo, Derecho, Sociedad y Riesgos. La Sociedad Contemporánea vista a través de la idea de riesgo (Brasilia, Centro Universitário de Brasília, 2007), pp. 13-64.

JaSAnOfF, Sheila, Civic Epistemology en JaSAnOfF, Sheila (coordinadora), Designs on Nature: Science and Democracy in Europe and the United States (Princeton, NJ: Princeton University Press, 2005), pp. 247-271.

Lorenzetti, Ricardo, Tratado de los Contratos. Parte General (Santa Fe, Rubinzal Culzoni, 2004).

Miraya Federico, Análisis de la legislación sobre ruido y vibraciones Disponible en : http://www.eie.fceia.unr.edu.ar/_acustica/biblio/legis.pdf [consultado el 20/08/2007].

NiviA, Elsa, Efectos sobre la salud y el ambiente de herbicidas que contienen glifosato, (2000) Disponible en http://www.rel-uita.org/Agrotoxicos [consultado el $15 / 07 / 2009]$.

RuluI, Jorge (compilador), Pueblos fumigados. Los efectos de los plaguicidas en las regiones sojeras (Buenos Aires, Del Nuevo Extremo, 2009). 
SierRA, Alfredo y NASSER, Marcelo, La responsabilidad del empleador por enfermedades profesionales de sus trabajadores. Enfoque jurisprudencial en Revista Chilena de Derecho 39 (2012) 1 pp. 57-76.

Silva, Anamaría - ARANCIBIA, Mariana - PULGar, Claudio et al., Exposición a plaguicidas $y$ prácticas de uso y protección en embarazadas de zona rurales en control de atención primaria en la región de Valparaiso, Chile, en Revista Chilena de Obstetricia y Ginecología 80 (2015) 5, pp. 373-380.

Silva Dreyer, Anamaría - Arancibia Mariana - Arnao Díaz, Maya et al., Exposición a plaguicidas y determinantes sociales de la salud en pequeños agricultores y agricultoras de la V Región Valparaiso, Chile en Revista Cuestiones de Población y Sociedad 7 (2016) 7, Año V, pp. 21-31.

Sozzo, Gonzalo, La prevención del daño (ensayo desde la mirada de las vías periféricas) en Revista de Derecho Privado y Comunitario 2 (2008).

Supiot, Alain, Derecho del Trabajo (Traducción de Patricia Rubini-Blanco, Buenos Aires, Heliasta, 2008).

Thayer Arteaga, William - Novoa Fuenzalida, Patricio, Manual de Derecho del Trabajo (Santiago, Editorial Jurídica de Chile, 1998).

\section{FUENTES}

Organización de las Naciones Unidas para la Agricultura y la Alimentación, Guidelines for Personal Protection when working with pesticidas in tropical climates (Disponible en: http://www.fao.org/ag/agp/agpp/pesticid/code/download/protect.doc [consultado el 27/07/2009], 1990)

Organización de las Naciones Unidas para la Agricultura y la Alimentación, Guía sobre seguridad y salud en el uso de productos agroquímicos (Ginebra, FAO, 1993).

Organización de las Naciones Unidas para la Agricultura y la Alimentación, (2008): "Perspectivas Alimentarias" documento semestral de FAO, junio 2008, Disponible en: http://www.fao.org/docrep/011/ai466s/ai466s00.htm [consultado el 27/07/2009].

Ministerio de Salud de Chile, Norma técnica de vigilancia de intoxicaciones agudas por plaguicidas. (Santiago, REVEP, División de Planificación Sanitaria, Departamento de Epidemiología, 2007).

Organización Internacional del Trabajo, Aumentan los riesgos para la seguridad y la salud de los trabajadores, advierte la OIT en Comunicado de Prensa, 22/04/1996, Ref. OIT/96/13. Disponible en: http://www.ilo.org/global/About the ILO/ Media and public information/Press releases/lang--es/WCMS 008410/index. htm [consultado el 19/09/2009]

Organización Internacional del Trabajo, Nuevo informe sobre la seguridad en la agricultura. Advertencia a los trabajadores agrícolas: los indices de mortalidad siguen siendo elevados y los pesticidas suponen un riesgo creciente para la salud, en Revista Trabajo de la OIT, 22, (Diciembre de 1997), disponible en: http://www.ilo.org/ public/spanish/bureau/inf/magazine/22/22farm.htm [consultado el 25/05/2013].

Organización Internacional del Trabajo, Seguridad y Salud en la Agricultura, en SafeWork (Junio de 2000), disponible en:

http://www.ilo.org/public/english/protection/safework/agriculture/brochure/spanish/ agricult s.pdf [consultado el 25/05/2013].

Secretaría De Ambiente y Desarrollo Sustentable La problemática de los agroqui- 
micos y sus envases, su incidencia en la salud de los trabajadores, la población expuesta por el ambiente. Estudio Colaborativo Multicéntrico (Buenos Aires, Secretaría de Ambiente y Desarrollo Sustentable, Organización Panamericana de la Salud, Asociación Argentina de Médicos por el Medio Ambiente, 2007)

Superintendencia de Riesgos de Trabajo, Indice Anual de Accidentabilidad Laboral según sector económico (1 dígito del CIIU), Año 2014. 